PRIFYSGOL

Journal Article

Promoting Well-being: Crisis, Loss and Alcohol

Livingston, $\mathrm{W}$ and Thompson $\mathrm{N}$

This article is published by SAGE Journals. The definitive version of this article is available at:

http://journals.sagepub.com/doi/abs/10.1177/1054137316668640

Recommended citation:

Livingston, W and Thompson N (2016) Promoting well-being: Crisis, loss and alcohol, Illness, Crisis \& Loss, Sept 2016. doi: 10.1177/1054137316668640. Available online: http://journals.sagepub.com/doi/abs/10.1177/1054137316668640. 


\title{
Promoting Well-being: Crisis, Loss and Alcohol
}

Wulf Livingston (1) and Neil Thompson (2)

(1) Glyndwr University, Wrexham, Wales, United Kingdom of Great Britain and Northern Ireland

(2) Avenue Consulting Ltd, Wrexham, Wales, United Kingdom of Great Britain and Northern Ireland

Corresponding Author:

Dr. Wulf Livingston, Senior Lecturer in Social Work Gwasanaeth Cymdiethiasol, PP13, Wrexham Glyndŵr University - Prifysgol Glyndŵr Wrecsam, Ffordd yr Wyddgrug Mold Road, Wrecsam Wrexham, Cymru Wales. LL11 2AW.

w.livingston@glyndwr.ac.uk

\begin{abstract}
Well-being is a concept which can connect together a number of important ideas that have a strong resonance for professional practice across the human services. This can critically include considerations of illness, crisis and loss (Thompson and Livingston, 2016). Such acute moments in individuals' lives can be examined through their precipitating events, coping mechanisms and responses. This paper explores some of the organisational and sociological dimensions of wellbeing and how they facilitate a greater understanding of illness, crisis and loss. These deliberations are then exemplified through a focus on alcohol and other drug use.
\end{abstract}

Keywords: well-being; crisis, loss, alcohol, drugs

\section{Introduction}

The term "well-being" is a useful integrative concept that enables us to explore ostensibly disparate elements as interconnected. Often well-being is equated with positive health and frequently explored in notions of welfare, but can be considered in essence as significantly different from both. It can encompass a range of considerations: emotional, spiritual, environmental, physical, social and workplace (Gamble 2013).

This diversity of interpretation allows holistic understandings to take shape. Importantly, it enables us to see acute experiences, such as illness, crisis and loss, through the multiplicity of events leading up to them, as well as a lens through which positive responses can be developed. Given the breadth of what well-being can encompass this creates a myriad of examples through which to explore this interconnectivity. For example, we can see that workplace pressures that lead to instances of breakdown and absenteeism can potentially be understood as a result of acute anxiety and can be resolved through stronger emotional well-being or mindfulness being developed. This article examines one example in detail, as a means of understanding these considerations, namely the 
significance of problematic alcohol and drug use. Analysis of alcohol and other drug use situations provides us with strong and helpful examples of the important relationships between well-being and experiences of illness, crisis and loss. .

The paper is in three parts. In the first we summarize some key understandings of well-being that have been detailed elsewhere in the literature. In doing this we offer one view of the diversity of the concept of well-being. The second part examines the relationship between well-being and illness, crisis and loss. It considers how (i) a lack of well-being is often a catalyst for acute trauma; and (ii) developing a stronger sense of well-being is significant in routes to recovery. This is then developed by exploring worker and client well-being with regards to the example of alcohol and drug use. In the third and final part we highlight some of the implications for professional practice, with specific regard to how holistic and solution-focused understanding enables a move away from unnecessarily ascribing individuals' inappropriate use of coping mechanisms as the problem and thereby pathologizing them.

\section{Notions of well-being}

Well-being is often a nebulous or ubiquitous term subject to some contesting and a range of possible definitions (Gamble, 2015; Seedhouse 1995). These divergences span narrow and subjective measurement or psychological perspectives with broader sociological and environmental critiques (Carlisle and Hanlon, 2007; Gamble 2015). Utilisation of well-being has been taken up by economists, environmentalists, health prevention, organisational studies, psychologists and sociologists. More recently, Thompson and Livingston (2016) have outlined a number of the more organisational and sociologically orientated considerations with regards to the human services. In this context, they argue that these relate to agency and practitioner experiences, on the one hand, and those of individuals in receipt of the services on the other. These two understandings are not mutually exclusive, as practitioners are affected by the well-being of those they work with and vice versa.

Workplace well-being is characterized by the need to respond to challenges, including those of absenteeism, bullying, harassment, stress and violence; and is preoccupied with establishing a quality of working life through staff care and employee well-being (Bolton and Houlihan, 2007; Fevre et al., 2013; Kinder et al., 2008; Robertson and Cooper, 2011; Schnall et al., 2009; Thompson and Bates, 2009). It is premised on a philosophy of human resources, with the emphasis on buman (Bolton and Houlihan, 2007; Thompson, 2013), recognizing that it is in the interests of all stakeholders for organizations to invest in the well-being of the workforce.

Client well-being is considered as a response to physical, psychological, existential and social challenges, and concerns itself with support, personal growth and empowerment. 
Taking workplace and client well-being as an overall framework, figure 1, captures a subjective summary of the potentially relevant and predominantly sociologically orientated characteristics 


\begin{tabular}{|c|c|c|c|}
\hline & Elements & Characteristics & Sources \\
\hline \multirow[t]{6}{*}{$\begin{array}{l}\text { Workplace } \\
\text { well-being }\end{array}$} & Stress & $\begin{array}{ll}\text { - } & \text { countertransference with client experiences of stress } \\
\text { - } & \text { supporting manageable workloads } \\
\text { - } & \text { avoiding pressures becoming excessive }\end{array}$ & $\begin{array}{l}\text { Cranwell-Ward and Abbey, } \\
2005\end{array}$ \\
\hline & Bullying and harassment & $\begin{array}{ll}- & \text { affects concentration and performance } \\
- & \text { countertransference with client experiences of harassment }\end{array}$ & $\begin{array}{l}\text { Bolton, 2007; } \\
\text { Stephens and Hallas, } 2006\end{array}$ \\
\hline & Violence & $\begin{array}{ll}- & \text { direct experiences of } \\
- & \text { exposures to others experience of } \\
- & \text { physical and psychological considerations }\end{array}$ & $\begin{array}{l}\text { Chappell and Di Martino, } \\
\text { 2006; } \\
\text { Newhill, } 2003\end{array}$ \\
\hline & Sickness absence & $\begin{array}{ll} & \text { higher error rates and absenteeism } \\
\text { - } & \text { physical, medical and other detriments as above } \\
\text { - } & \text { pressure on other staff well-being (vicious cyclical process) }\end{array}$ & $\begin{array}{l}\text { Collins, 2008; Cranwell-Ward } \\
\text { and Abbey, } 2005\end{array}$ \\
\hline & Work-life balance & $\begin{array}{l}\text { the resolution or reinforcement of tensions between home-based } \\
\text { pressures and work-based demands } \\
\text { - } \quad \text { managing boundaries between the two } \\
\text { - } \quad \text { ensuring sufficient breaks from work are taken }\end{array}$ & $\begin{array}{l}\text { Ayre and Preston-Shoot, } 2010 \\
\text { Thompson et al, } 2008\end{array}$ \\
\hline & $\begin{array}{l}\text { Organization as } \\
\text { community }\end{array}$ & $\begin{array}{ll}\text { - } & \text { occupational social work and occupational health } \\
\text { - } & \text { individuals employed to respond to human relations problems that arise } \\
\text { in the workplace } \\
\text { - } \quad \text { conflict, substance use, mental health, grief, loss, trauma, illness }\end{array}$ & $\begin{array}{l}\text { Bennis et al, 2005; Desai, } \\
\text { 2009; Ghodse, 2005; Orcutt } \\
\text { and Rudy, 2003; Thompson } \\
2009\end{array}$ \\
\hline \multirow[t]{3}{*}{$\begin{array}{l}\text { Client well- } \\
\text { being }\end{array}$} & Social & $\begin{array}{l}\text { - making a commitment to social amelioration, especially in relation to } \\
\text { the promotion of social justice } \\
\text { - } \\
\text { supporting the development of meaningful and sustainable social } \\
\text { activities and networks } \\
\text { - } \quad \text { problem-solving and solution-focused approaches }\end{array}$ & $\begin{array}{l}\text { Gamble, 2013; } \\
\text { Thompson, 2016a }\end{array}$ \\
\hline & Environmental & $\begin{array}{ll}\text { - } & \text { deep ecology } \\
\text { - } & \text { sustainable environments (micro and macro) as prerequisite for well- } \\
\text { being } & \\
\text { - } & \text { environmental crisis and disasters as threats to well-being and } \\
\text { opportunities for individual and community growth }\end{array}$ & $\begin{array}{l}\text { Dominelli, 2012; } \\
\text { Jamieson, } 2003\end{array}$ \\
\hline & $\begin{array}{l}\text { Psychological and } \\
\text { emotional }\end{array}$ & $\begin{array}{l}\text { - understanding difficult experiences of behavior, cognition and feelings } \\
\text { as responses to stress as much as problems }\end{array}$ & $\begin{array}{l}\text { Thompson and Livingston, } \\
2016\end{array}$ \\
\hline
\end{tabular}

Figure 1 - Summary of elements and chrematistics of broad range of well-being considerations 


\begin{tabular}{|l|l|r|l|}
\hline & Spirituality & - can be associated with formal religion but is not dependent upon & $\begin{array}{l}\text { Furness and Gilligan, 2010; } \\
\text { Gray, 2006; Holloway and } \\
\text { Moss, 2010 }\end{array}$ \\
\cline { 2 - 5 } & Welfare & $\begin{array}{l}\text { wide concept about intangible goods produced from our inter- } \\
\text { relationship } \\
\text { neoliberal ideas of individualism and welfare benefit recipients }\end{array}$ & Jordan 2007; 2008 \\
\cline { 2 - 5 } & Young people & - safety (protection from harm) and growth & Bradshaw and Mayhew, 2005 \\
\cline { 2 - 5 } & Quality of provision & $-\quad$ workers underperforming, absent, changing workers & Collins, 2008 \\
\hline
\end{tabular}

Adapted from Thompson and Livingston 2016 


\section{Of illness, crisis and loss}

Well-being when seen through this lens encompasses a range of human experiences. These are often the spaces where individuals encounter acute difficulties and challenges. Illness, crisis and loss can all be seen as moments where well-being is not being sustained, is under threat, no longer present or present to a lesser extent. They can further be considered as opportunities to respond through supporting the growth of well-being. This chimes well with theories of crisis intervention (Thompson, 2011a), transformational grief (Schneider, 2012) and post-traumatic growth (Tedeschi and Calhoun, 2004), each of which shares the theme of the belief in the importance of investing time and effort into producing positive outcomes from negative circumstances.

Perhaps the most simple of conversations is that related to health. In this sense, ill health comes to be seen as the opposite of wellness or good health. So, illness can be seen to occur physically when well-being breaks down, and it is recovered from through the promotion and support of well-being. This seems obvious in the sense of physical health, and is, as such, reflected in the language of disease models and medical approaches. The body ceases to be well, and is then deemed to be ill, before becoming cured or restored to a point of healthiness where possible. This is, of course, the "get well soon" perspective. It applies equally, however, to emotional, spiritual or psychological wellness. Here the "illness" is also traditionally seen as a breakdown of well-being (this time, mental wellbeing), often with a diagnostic pathway leading to a course of treatment of some description. This in turn leads to the possibility of psychological or emotional well-being expressed in terms of recovery from a mental illness (Pilgrim and McCranie, 2013).

Crisis, typically those moments when normal coping mechanisms are insufficient to deal with presenting circumstances, might equally be seen as the instance when well-being is no longer sustainable (Thompson, 2011a). Work is often a difficult experience for many people, but one that is normally endured for the most part. However, for some individuals it can become a critical experience, a crisis potentially resulting in physical and mental health problems. By contrast, where there are more rewarding work experiences, or following a restoration from a position of an overly pressurized work situation, normal coping mechanisms thrive to support personal, professional and social well-being. Equally, other aspects of life can be challenging and present a scenario of aiming for surviving, rather than flourishing. For individuals these too can be moments of crisis where a breakdown in the homeostasis of the body, mind and social functioning results in high 
levels of difficulty in functioning. Such crises are similarly resolved through the support and maintenance of well-being across a range of the domains.

Death, dementia, disability, divorce, homelessness and retirement, while potential moments of crisis and illness, also represent episodes of potentially acute loss. Simply put, we might consider many of the losses supported in the human services as losses of an aspect of well-being (Thompson, 2012).

Well-being can help us explore these three critical considerations for the experiences of those working within the human services, as well as those worked with. An important feature of this orientation around well-being is that it fits well with responding to acute trauma as a belief in holistic relationship-based interventions geared towards problem solving and empowerment, as opposed to the managerialism-driven approaches that focus on narrow care management processes. This means, for all those involved, a focus on positive change, rather than consumerist processes of service delivery and the rationing of scarce resources (Thompson, 2016a). We now explore these general considerations of illness, crisis and loss with regards to the example of individuals who experience alcohol and other drug use difficulties and those personnel who work with them. In the acutest form this will be specialist alcohol and drug services, but given the inherent prevalence of use also means a much wider range of health, organisational and social care professionals.

\section{Escapism and recovery: cause and solution - alcohol and drug use as an exemplar}

Alcohol and drug use is integral to most societies (Gossop, 2013), and problems associated with it are manifest (Davies et al., 2012) and frequently end up being the concern of human services professionals (Livingston and Galvani, 2014). Traditional medical responses to this situation see such problematic use as the flawed behavior of ill people, which, if treated correctly, will then result in improved health. More recently, much of UK governmental policy has added to this a preoccupation with the tension between managing legal economic markets of alcohol and drug consumption, with limiting negative health, social and workplace costs (Davidson, 2013). These approaches emphasize the sense of two distinct populations: legitimate normal healthy users and inappropriate misbehaving addicts. However, these simplistic interpretations do not explore the integrated contexts of why individuals use, the complications that flow from such use and how they might build more sustainable lifestyles (Alexander, 2010; Orford 2013). Nor do they help us understand how they contribute to experiences of illness, crisis and loss and how improving well-being can help to avert such situations. 
Problematic alcohol and drug use can be seen as a reflection of wider social ills (poverty, homelessness, unemployment, discrimination and so on) that have an impact on individuals, families and communities. Sustained, long-term excessive use of alcohol and other drugs leads to a range of physical, psychological and social dependencies. Again, in the most obvious sense this can entail physical illness - for example, cancer, cirrhosis, heart disease and/or sight loss. Psychological manifestations are well articulated too, such as: depression, Korsakoff syndrome and psychosis. These are perhaps those of the acute using population; however these consequences can also be extended into a lack of emotional well-being, manifesting itself as challenges of anger management, anxiety, confidence, and self-esteem. There can be spiritual consequences too, in so far as efforts to find meaning, purpose and direction can be side-tracked by problematic use of alcohol or other drugs (and, to a certain extent, such spiritual challenges have the potential to be contributory factors to problematic substance use in the first place). Finally, sustained use will also result in difficulties associated with child care, education, employment, family life and relationships. While these lists are not exhaustive, and many other consequences of use could be added, they are illustrative of the extent to which alcohol- and drug-induced illness and other complications can be seen as reflections of breakdowns in well-being. In this context they reflect a wider population, and as such use can also be viewed as a response to poor well-being: alcohol use to relieve back pain; heroin to block out memories of abuse; or cocaine taken to gain confidence.

For some, but not all these experiences will lead to increasingly sustained levels of use, even dependency, and these in turn often culminate in moments of acute crisis. Accident and emergency, acute psychiatric admission and police callouts often involve moments of alcohol and drug consumption, if not reflect a build-up of years of use. Indeed the notion of hitting "rock bottom" inherent in the disease model of addiction could be seen as an expression of such crisis scenarios. In these situations, it is possible to consider individuals as having levels of well-being so depleted as to tip the homeostatic scales of coping. Concepts of loss and trauma are linked with alcohol and other drug use (Galvani et al 2016). Any attempt to change substance use behavior entails a new primary loss; that of giving up substance use as a coping mechanism. But often this is really about coping with a more deep-seated primary loss or set of losses relating to: body (abuse), confidence, dignity, home, job, respect and self-respect. Many of the consequences of use then lead to other losses, as described above, in relation to health, cognition, feelings and social support. These consequential losses can also be acute and, in turn, engender moments of 
crisis - in particular, loss of liberty (imprisonment or compulsory psychiatric admission) or removal of children via child protective services. Again, the presentation of these needs is made across a range of services beyond the specialist. In turn, we can also then consider this as compound losses across of a range of the well-being considerations identified earlier within this paper.

However, and crucial to this paper's argument, is the assertion that considerations of wellbeing also offer the prospect of addressing illness, crisis and loss concerns and difficult experiences of alcohol and drug use. So, if we step away from the traditional primary focus on the problematic consequences of consumption and, instead, focus on developing, improving and restoring physical, psychological and social functioning, we are more likely to break some of these cycles of compounding difficulties. Simply put, a life that is rich in the rewards of well-being is far less likely to then make individuals feel a need to engage in sustained excessive and destructive levels of alcohol and drug use.

This understanding is paralleled in the emerging discourses about recovery, that are becoming increasingly influential in mental health and alcohol and drug use considerations (Pilgrim and McCranie, 2013; Roth and Best, 2012; Tew et al., 2012).

These conversations begin with a focus on some of the traditional behavioral and problemrelated service provisions, and attempt to turn them into recovery-orientated systems of care and support. For these services this is often about extending the existing treatment outputs to include consideration of well-being-related outcomes. The shift is not a fundamental one; rather, it is a broadening of the curative or restorative functions of treatment. However, other recovery dialogues include a move to more acknowledgement of sustained lifestyle change and promotion of growth to a situation better than that before the illness, loss and crisis. In this context, this is about using a holistic understanding of well-being, and support of its development with a view to not only producing happier and healthier individuals, but also to establishing a sustainable communities and frameworks that breaks some of the existing vicious circles of dislocation and substance use. This latter form of recovery often focuses on wider notions of community and peer-led activities, and has connection with some of the social justice considerations of well-being (Gamble 2015, Thompson and Livingston 2016).

This focus on developing what is often referred to as recovery capital (Best and Laudet, 2010), includes considerations of where illness, loss and crisis can also be seen to overlap with well-being and alcohol and drug use in the spheres of spirituality and mindfulness. Many of the peer-led community programs, most notably Alcoholics Anonymous, have an 
explicit reference to the role of spirituality in the recovery process. This can include both formal religious interpretations and informal individualized ones (Kurtz, 1991). There is a significant role played by religious and spiritual groups in the provision of less formal community service provision and support. The development of a greater sense of mindfulness becomes the acquisition of a psychological and emotional well-being that helps provide resilience to possible causes of "ill-being" (Orsillo and Roemer, 2011).

\section{Some Implications}

Thompson and Livingston (2016) highlight the importance of considering worker wellbeing. These considerations can be actively considered in the light of those who work directly with people having difficulties with alcohol and other drug use. Such work not only involves the exposure to others' experiences of illness, crisis and loss, as described above, but also directly (and often consequentially) affects practitioner and organizational well-being.

Best et al. (2016) suggest that workers in this sector experience high levels of burnout (reflected in crises and poor well-being). This leads to a range of health issues, as well as poor job performance, absenteeism, and staff turnover. They suggest that various factors contribute to this situation, including demanding clients, the work environment, job factors, and clinician sociodemographic factors. This, in turn, results in a danger of the gamekeeper turning poacher. In other words, these experiences of a lack of workplace well-being can lead professionals themselves to feel the need to meet these pressures with increases in their own use of alcohol and other drugs (Ghodse, 2005; Livingston, 2016; Orcutt and Rudy, 2003). The same compounding processes of interconnectivity whereby a lack of well-being fuels substance use, resulting in a greater lack of well-being can occur for the professional too. Similarly, this can lead to some of the illness, crisis and loss problems described above (a reversal of the notion of "Physician heal thyself").

In terms of supporting worker well-being, Best et al. (2016) suggest greater perceived developmental opportunities and the extent of support systems workers have access to will significantly affect whether or not professionals working with those using alcohol and other drugs experience burnout. A workplace that fosters employee well-being is likely to ensure that such professionals have a strong sense of resilience to, and reward from, their workplace activities.

Whether services should focus on an illness-based medical model of addiction, rather than well-being, is a highly contested matter. Like mental health there are strong movements emphasizing the need for greater person-centred practice, a stronger recovery orientation 
and higher levels of client involvement. These calls suggest that treating the presenting problem, the substance use, is often prioritized and resourced at the expense of concentrating on the underlying causes and the support of new and healthier alternative lifestyles, which in turn promote and support well-being..

This paper suggests that: (i) we currently spend considerable time attempting to fix deficits in well-being as responses to illness, crisis and loss; and (ii) a more holistic understanding of moments of acute trauma (including seeing them as reflections of wider issues) that supports a strengths-based approach to fostering well-being would enable a more sustainable prevention-orientated approach to practice.

Given the potential diversity and integrative possibilities of well-being, there is only a slow emergence of the development of measures of attribution or outcomes. Recovery (sustained well-being) is, by its nature, longitudinal and requires input, effort and evaluation long after acute illness, loss and crisis services have receded. It is perhaps much more complicated to evaluate, as it is a multidimensional approach informed by sociological considerations as well as psychological or biological ones. It is far easier to identify (sooner) a change in drinking than an improved relationship with previously estranged family members. Traditional biological and psychological treatment-focused responses to "symptoms" have in part remained dominant because they lend themselves in policy, research and performance conversations to much more precise measurement. If better well-being lies at the core of sustainable solutions and it is a diverse concept, then the understanding of its efficacy needs to come in greater recognition of new evaluation methodologies. Clearly, evaluating what is easy to measure because it is easier to measure is not a helpful way forward.

Alcohol and drug use can be seen as a response to poorer well-being across many of the domains. Much of this use is located within the dislocation and poverty of spirit that affects individuals and society (Alexander, 2010). Resolving these biopsychosocial manifestations is well served by the social justice orientation of many of the human services, and social work in particular (Gamble 2015). As Thompson and Livingston (2016) articulate, this involves an acknowledgement by services and practitioners of barriers (personal, cultural and structural) to achieving well-being, which can be addressed working in partnership (working together to identify the barriers and develop plans for addressing them); and empowerment (supporting people in developing more control over their lives in and by addressing the barriers concerned). 
It is essential to incorporate consideration of these wider elements in order to avoid the simplistic individualistic model of well-being rightly criticized by Cederstrőm and Spicer (2015). Many populist narratives around well-being (or "wellness") overemphasize the role and responsibility of individuals and, in so doing depoliticize and oversimplify complex issues. It is therefore essential to distinguish our holistic, social scientific approach to wellbeing from this simplistic Sunday supplement mentality.

Perhaps the straightforward message that we are putting forward here is that much illness, crisis and loss can be both avoided and/or supported through the promotion of well-being in practice, which in turn would contribute to a reduction in some of the more damaging incidences of alcohol and drug use. It is further emphasized that this focus needs to be a holistic one, incorporating wider cultural and structural factors to avoid a narrow and atomistic understanding of well-being that fails to do justice to the complex sociopolitical factors involved (Thompson, 2011b).

\section{Conclusion}

Well-being can be explored as a diverse integrative concept that helps us to develop a wider and deeper understanding of illness, crisis and loss. This can be seen in many examples. However, experiences of alcohol and other drug use serve well to illustrate that well-being as an explanation of, and response to, acute moments of difficulty; can be seen in the context of a set of important factors relating to clients, practitioners and organizations. As an explanation, it supports many of the more recent arguments for alcohol and drug use to be seen as an understandable response to dislocation, whether this be whole-scale environmental and social displacement or individual physical, psychological and social disruption (Alexander 2010; Orford 2013). As a solution, it suggests that the basic humanistic foundation of the human services can be seen as way to reaffirm important concerns and enrich quality of life in important ways at a variety of levels.

\section{References}

Alexander, B. (2010). The globilisation of addiction: A study in poverty of the spirit. Oxford:

Oxford University Press.

Ayre, P. and Preston-Shoot, M. (2010). Children's services at the crossroads: A critical evaluation of contemporary policy for practice, Lyme Regis, UK: Russell House Publishing.

Bennis, W., Cloke, K. and Goldsmith, J. (2005). Resolving conflicts at work: Eight strategies for everyone on the job. San Francisco, CA: Jossey-Bass.

Best, D and Laudet, A. (2010). The potential for recovery capital. London: Royal Society for the Arts. 
Best, D. Savic, M and Daley, P (2016). The well-being of alcohol and other drug counsellors in Australia: Strengths, risks, and implications. Alcoholism Treatment Quarterly, $34: 2,223-232$,

Bolton, S. C. (ed.) (2007). Dimensions of dignity at work. London: Butterworth-Heinemann.

Bolton, S. C. and Houlihan, M. (eds) (2007). Searching for the human in human resource management, Basingstoke, UK: Palgrave Macmillan.

Bradshaw, J. and Mayhew, E. (2005). The well-being of children in the UK, $2^{\text {nd }}$ edn. London: Save the Children.

Cederstrôm, C. and Spicer, A. (2015) the wellness syndrome. Cambridge, UK: Polity Press. Collins, S (2008) Statutory social workers: Stress, job satisfaction, coping, social support and individual differences. British Journal of Social Work 38 (6) 1173-1193.

Chappell, D. and di Martino, V. (2006). Violence at work, $3^{\text {rd }}$ edn, Geneva: International Labour Office.

Cranwell-Ward, J. and Abbey, A. (2005). Organizational stress. Basingstoke, UK:

PalgraveMacmillan.

Davidson, R. (2013). Formulating effective alcohol policy: Not as simple as it sounds. In Mistral, W. (2013) Emerging perspectives on substance misuse. Oxford: Wiley Blackwell, 23-39.

Davies, C., English, I., Lodwick, A., McVeigh, J. and Bellis, M. A. (Eds.) (2012). United Kingdom drug situation: Annual report to the European Monitoring Centre for Drugs and Drug Addiction (EMCDDA). London: Department of Health.

Desai, S. (2009). Mental health problems, in Thompson, N. and Bates, J. (Eds.) Promoting workplace well-being. Basingstoke, UK: Palgrave Macmillan.

Dominelli, L. (2012). Green social work: From environmental crises to environmental justice.

Cambridge, UK: Polity Press.

Fevre, R., Lewis, D., Robinson, A. and Jones, T. (2013). Trouble at work. London: Bloomsbury.

Furness, S. and Gilligan, P. (2010). Religion, belief and social work: Making a difference. Bristol, UK:The Policy Press.

Gamble, D, N (2013) Well-being in a globalized world: Does social work know how to make it happen? Journal of Social Work Education 48 (4) 669-689.

Ghodse, H. (ed.) (2005). Addiction at work: Tackling drug use and misuse in the workplace, Aldershot, UK: Gower.

Gossop, M. (2013). Living with drugs. 7th edn. Farnham, UK: Ashgate. 
Gray, M. (2006). Viewing spirituality in social work through the lens of contemporary social theory. British Journal of Social Work, 38 (1). 175-196.

Holloway, M. and Moss, B. (2010). Spirituality and social work. Basingstoke, UK: Palgrave Macmillan.

Jamieson, D. (ed.) (2003). A companion to environmental philosophy. Oxford: Blackwell. Jordan, B. (2007). Social work and well-being. Lyme Regis, UK: Russell House Publishing. Jordan, B. (2008). Welfare and well-being: Social value in public policy. Bristol, UK: The Policy Press.

Kinder, A., Hughes, R. and Cooper, C. L. (eds) (2008). Employee well-being support: $A$ workplace resource. Chichester: Wiley.

Kurtz, E. (1991). Not-god; A bistory of Alcoholic Anonymous. San Francisco, CA: Hazelden. Livingston, W. (2016) The acquisition and use of non-codified knowledge by social workers - alcohol, a case study. Practice: Social Work in Action - advanced access online http://dx.doi.org/10.1080/09503153.2015.1135894

Livingston, W. and Galvani, S (2014). Using evidence to inform working with people who misuse substances, in Webber, M. (ed.) (2014). Applying research evidence in social work. practice. Basingstoke, UK: Palgrave Macmillan.

Moss, B. (2005). Religion and spirituality. Lyme Regis, UK: Russell House Publishing.

Newhill, C. E. (2003). Client violence in social work practice: Prevention, intervention, and research. New York: The Guilford Press.

Orcutt, J. D. and Rudy, D. R. (eds) (2003). Drugs, alcohol, and social problems. Oxford: Rowman \& Littlefield.

Orford, J. (2013). Power, powerlessness and addiction. Cambridge, UK: Cambridge University Press.

Orsillo, S. M. and Roemer, L. (2011). The mindful way thorugh anxiety: Break free from chronic worry and reclaim your life. New York: The Guilford Press.

Pillgrim, D. and McCranie, A. (2013). Recovery and mental health: A critical sociological account. Basingstoke: Palgrave Macmillan.

Robertson, I. and Cooper, C. (2011). Well-being: Productivity and happiness at work. Basingstoke, UK: Palgrave Macmillan.

Roth, J. and Best, D. (Eds.) (2012) Addiction and recovery in the UK. London: Routledge. Seedhouse, D (1995) 'Well-being': health promotion's red herring. Health Promotion International 10 (1): 61-67. 
Schnall, P. L., Dobson, M. and Rosskam, E. (eds) (2009). Unhealtby work: Causes, consequences, cures, Amityville, NY: Baywood.

Schneider, J. M. (2012). Finding my way: From trauma to transformation: the Journey through loss and grief, Traverse City, MI: Season's Press.

Stephens, T. and Hallas, J. (2006). Bullying and sexual harassment. Oxford: Chandos.

Tedeshi, R. G. and Calhoun, L. G. (2004). Posttraumatic Growth: Conceptual Foundation and Empirical Evidence. Philadelphia, PA: Lawrence Erlbaum Associates.

Tew, J., Ramon, S., Slade, M., Bird, V., Melton, J. and Le Boutillier, C. (2012) Social

Factors and Recovery From Mental Health Difficulties: A Review of the Evidence. British Journal of Social Work, 42 (3), 443-460.

Thompson, N. (2009). Loss, grief and trauma in the workplace, Amityville, NY: Baywood. Thompson, N. (2011a). Crisis intervention. Lyme Regis, UK: Russell House Publishing. Thompson, N. (2011b). Promoting equality: Working with diversity and difference. $3^{\text {rd }}$ edn, Basingstoke, UK: Palgrave Macmillan.

Thompson, N. (2012). Grief and its challenges. Basingstoke, UK: Palgrave Macmillan. Thompson, N. (2016a). The professional social worker: Meeting the challenge, $2^{\text {nd }}$ edn. London: PalgraveMacmillan.

Thompson, N. (2016b). The authentic leader. London: Palgrave Macmillan.

Thompson, N. and Bates, J. (eds) (2009). Promoting workplace well-being. Basingstoke, UK: Palgrave Macmillan.

Thompson, N and Livingston W (2016) Promoting Well-being Illness, Crisis \& Loss, http://icl.sagepub.com/content/early/2016/04/13/1054137316643445.full.pdf + html Thompson, N., Ng, S-M. and Yau, P. (2008). Work-life balance: Lessons from the United Kingdom and Hong Kong. Journal of Psychology in Chinese Societies, 9(1).

Travers, P. and Richardson, S. (1997). Material well-being and human well-being, in Ackerman, F., Kiron, D., Goodwin, N. R., Harris, J. M. and Gallagher, K. (eds) Human well-being and economic goals. Washington DC: Island Press.

Wilkinson, R. and Pickett, K. (2010) The spirit level: Why more equal societies almost always do better, London: Penguin. 